\section{A theoretical approach to the demand and supply of peacekeeping}

\section{Vincenzo Bove}

$\mathrm{T}$

he post-cold war years have been marked by a variety of external interventions in civil conflicts. The empirical judgement on the overall performance of U.N. peacekeeping is mixed and shows that military instruments may be ineffective and sometimes counterproductive for the recovery of war-torn societies. ${ }^{1}$ On the one hand, this may be explained for example by a lack of agreement on what would have happened without a deployment and a lack of understanding of the conditions leading to peace. On the other hand, the empirical work may be based on a relatively weak theoretical understanding of peacekeeping. Thus, this article first further develops the theory of peacekeeping, and it argues that the interaction between the demand for peacekeeping, i.e., factors pertaining the nature of the conflict, and the supply of peacekeeping troops, i.e., the economic and political factors affecting states' ability and willingness to contribute to peace operations, jointly determine the outcome of such operations. It is this interaction that needs to be explored to explain theoretically and empirically which factors and circumstances leads to peacekeeping success.

On the demand side, to understand how to bring about peace, one has to understand how a war begins. In the literature on civil war, individual gains are one of the most immediate understandable causes of civil wars. ${ }^{2}$ Consequently, the economic motivations for war are better theorized than any other factor, leading to a vast literature on conflict models. But there is still no consensus on how one should analytically characterize peacekeeping as an activity and how one should integrate a third party external intervention into traditional two-party models of conflict, especially how a third party can change the various incentives of combatants away from warfare. In the traditional bilateral conflict models, for instance of Hirshleifer, Grossman, or Skaperdas, the warring factions are viewed as rational decisionmakers who choose conflict or cooperation, depending on which is more profitable on the margin. $^{3}$ This approach takes anarchy, i.e., the absence of property rights protection, and the agents' set of preferences as given, and focuses on how many resources are devoted to "appropriative activities" in equilibrium. When introducing a third party into these models, one can show how this can lower the level of hostility by altering the elements underlying the choice between conflict and cooperation, such as rentseeking and the financial viability of the conflict, and thus solve the dispute. The results suggest that intervention is most likely to succeed when the third party can convince the belligerents (1) that resistance to settlement is costly; (2) that success can be impossible; and (3) that the cost of complying with coercive demands is a price they can afford to pay. It can be shown that limiting the scope of conflict and enforcing an agreed settlement is only feasible with the third party's credible authority to regulate the conflict and, if necessary, to inflict heavier damage to any one conflict side than would otherwise be the case. $^{4}$

Nonetheless, in many cases of unsuccessful coercion, the third party's threats may well be credible and carried out exactly as promised and yet may not be sufficient to produce compliance. A poor knowledge of what combatants value and how they make decisions can result in strategic failure. Thus, it is crucial to also understand what the belligerents value and how committed they will be to resisting an external action. Indeed, overconfidence, wrong perceptions, and the desire for vengeance can hamper any attempt to settle a dispute. To understand the limitations of peacekeeping, and the obstacles to the demand for peacekeeping, the first part of this article focuses on wrong perceptions and malevolence, two neglected aspects in the literature on third party intervention. A framework is developed to synthesize the problem of overconfidence; the framework also explains how human preferences, such as the desire for vengeance, contributes to conflict escalation.

Understanding how countries decide to intervene is central to evaluating the success or failure of operations as well. Therefore, having discussed some aspects of peacekeeping on the demand side, one needs to understand the desire of actors to intervene. Determining the objectives of the intervening governments is difficult because the stated goal often reflects a rhetoric of intervention and may not mirror the true objectives. Moreover, given the variety of domestic and international factors that determine a country's contribution to military peacekeeping, there must be a question as to whether their motivation can be captured in a simple objective function suitable for mathematical analysis. Nonetheless, the second part of this paper is on the supply side and attempts to capture some conditions determining countries' contributions to peace missions.

\section{Wrong perceptions and irrational behavior}

Standard economic models of conflict assume that asymmetry in military capabilities, and fighting efforts, determines the relative degree of conflict success. Individual preferences play a role only in relation to material returns and punishment. There are two exceptions. First, a civil war may also present asymmetry of information. The parties in a conflict act on the basis of perceptions, because they cannot truly know the relative cost and benefit of war. The belligerents are vulnerable to systematic errors in decisionmaking, such as overestimating their chances of winning. Brauer 
(2006) suggests that this problem can be compared to information failures in financial markets, when information is insufficient, incorrect, or impossible to process. If the problem of asymmetric information is not addressed, a successful third party intervention may not be possible. Second, although economists view war as a process of rational calculation by combatants, actions can be motivated by a consistent set of seemingly irrational human behavior, such as hatred and vengeance. When the parties in dispute are inspired by deep feelings of ideological, religious, or ethnic hatred, reaching compromise may become impossible. When the historical record of past attempts is poisoned by betrayals and failures, as for instance in the case of the Arab-Israeli conflict, radicalized preferences may hamper the willingness to believe in the other side's good will and the desire for settlement. This requires the third party to understand what the belligerents value and how committed they may be to resisting an external action.

Overconfidence

If everyone agreed on the expected outcome of any dispute, there would be no need to fight. In particular, if the weaker side had full knowledge of its relative condition, it would surrender and the conflict would cease. But when the two sides do not agree on how much damage they are likely to inflict on each other, conflict ensures. This is partly due to overconfidence, the overestimation of one's own relative ability and/or the underestimation of the rival's ability. Consider a conflict between two agents, a government and a rebel movement, and suppose that they differ in fighting ability. The higher ability agent obtains a higher return when he wins. Agents' ability are referred to as their "types," the real value of which is disclosed when the war is over. Assume that any agent's subjective belief about its own type is not equal to the true type, and that this subjective belief is private information. Moreover, the agents do not know that they and their rival are overconfident in their own types. Each belligerent's fighting effort is chosen to maximize its expected resource partition on the basis of prior and subjective information about its type. Further assume that the overestimation of one's type increases one's effort: The agent behaves as if it has a higher type and, since the effort strategy is increasing in types because the agent believes victory is more likely, it chooses a higher effort.

The true probability of winning depends on the probability that one's own type is no lower than that of the rival. During the course of the conflict each party constantly reassesses its probability of winning in response to new information regarding the progress of the war, and because each side may have different information available to it, an agent's subjective probability of winning the war need not to be symmetrical, as standard economic models assume. This means, for example, that a decrease in the government's subjective assessment of its probability of winning does not necessarily imply an equivalent increase in the rebels' assessment of their probability of victory.

This dynamic may be shown by means of an easy example. Building on Wittman
(1979), in Figure 1, $\mathrm{S}_{\mathrm{G}}$ in the settlement region on the horizontal axis indicates an unconditional surrender by government and corresponds to its lowest level of utility on the vertical axis, while $S_{M}$ means an unconditional surrender by the rebels. Now suppose rebels begin with a low subjective probability of winning (point $A$ ) and thus a low expected utility from continuing the war, indicated by the dashed line and the number 1 near the left vertical axis. Government will only agree to a settlement if it is located to the right of $\mathrm{C}$ (where $\mathrm{C}$ is chosen for purposes of illustration) because to the right of $C$ its utility increases. Because the settlement region to the left of $A$ gives rebels more utility than at $\mathrm{A}$, both parties are better off between points $\mathrm{C}$ and $\mathrm{A}$, and a negotiated settlement is feasible. However, if rebels overestimate their own type and believe hat they are more likely to win, thus receiving more utility (from utility 1 to utility 2), their demands in any negotiations increase (shift from A to B). If at the same time, government's subjective probability and minimal demands remain unchanged, then the rebels' relative optimism about the outcome of war renders settlement impossible, because no longer is there an overlap between the area to the right of $\mathrm{C}$ and that to the left of $\mathrm{B}$.

Figure 2 shows the opposite dynamic. As rebels' subjective probability of winning decreases (the vertical arrows pointing down), so does their minimal demand which moves to the right (from 1 to A). At the same time, the government's subjective probability of winning as well as its minimal demand decrease, moving to the left (from 2 to B). As both minimal demands move favorably, settlement becomes more likely because the settlement region expands: The area between points A and B is wider than the area between 1 and 2. This indicates that there is more room for settlement. Obviously, if one side's increase in subjective probability of winning were to exactly offset the other side's decrease in subjective probability of winning, there would be no change in the settlement region. These examples show that, unless both parties perceive that a peaceful settlement can make them better off, fighting is likely to continue.

To reach peaceful settlement, a third party can try to modify either conflict party's expected utility from continuing war by changing its subjective probability of winning. This may be done by undertaking actions against one party to inflict heavy damage and increase the perceived cost of pursuing war (e.g., the strategic bombing of military areas). As argued by Regan (1996, p.341) "the key to any intervention strategy is to alter the calculation by which the antagonists arrive at a particular outcome." When a party faces a decrease in its subjective probability of winning, its minimal acceptable demand is reduced. Third party intervention is a process that involves bargaining with the aim to compel both parties to sit at the negotiation table. Thus, being prepared to inflict unacceptable damage on either party, and making sure it is aware of the risk, increases the perceived cost of war and lowers the expected probability of a successful outcome. A settlement of war is then more likely. Clearly, the influence of a third party can be counterinfluenced by recourse to a fourth party. This happened for instance during the cold war era, when East and West battled by 


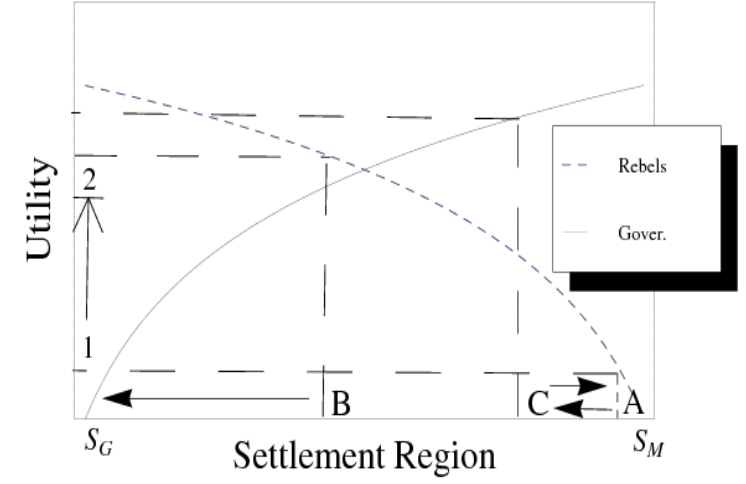

Figure 1: Contracting settlement region.

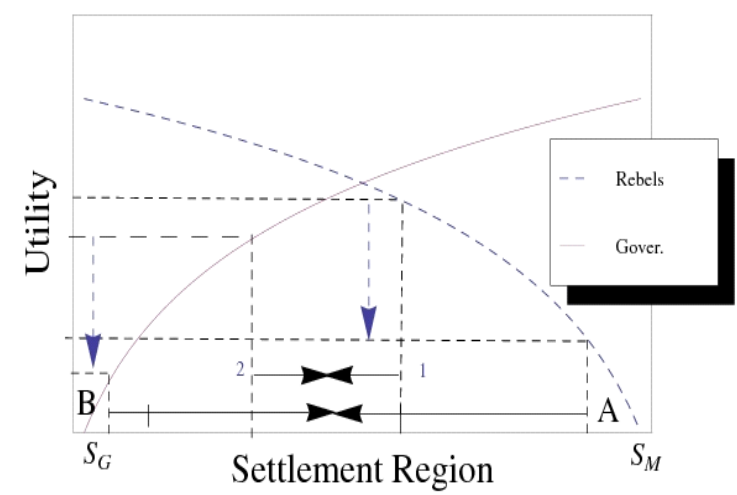

Figure 2: Expanding settlement region.

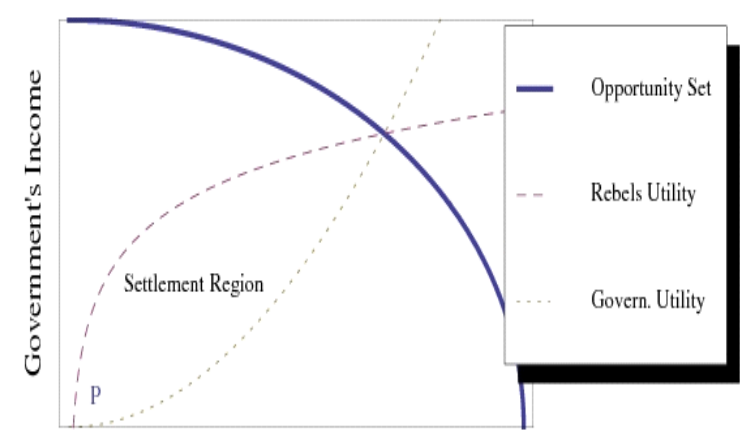

Rebels' Income

Figure 3: Malevolent preferences. proxy, turning friends and allies abroad into warriors in their own behalf.

Preferences and the role of vengeance

The desire for vengeance is a powerful force driving many conflicts. People are likely to differ in their notions of fairness and the appropriate level of punishment and retaliation. Retaliatory actions often incur costs that are out of proportion to the harm that initiated the conflict in the first place. Revenge is often tied to the self-worth of the originally offended individual. ${ }^{5}$ Individuals with little power may seek revenge against more powerful adversaries even though this action may incur overwhelming costs. One may model this in terms of malevolen behavior whereby an agent willingly sacrifices income to make the other party poorer. This may be seen in Figure 3, based on Hirshleifer (1999). Government's income is scaled along the vertical axis, and rebels' along the horizontal axis. Both wan to achieve as high a position as possible. The concave curve in bold type font reflects the upper bound of the settlement opportunity set, a range of peaceful outcomes attainable if war is avoided. Point $\mathrm{P}$ is the mutual perceived utility from continuing war. Instead of government being concerned only with maximizing its income, and rebels only with maximizing theirs, each party now attaches a positive utility to the other's material impoverishment. Each side is ready to incur a material sacrifice to reduce the other's well-being. Thus, the indifference curve now has a positive slope. Because reciprocal malevolence reduces the settlement region, and fighting is more favorable than are the terms of any conceivable peace treaty, it becomes difficult to sufficiently alter the costs and benefits to induce cooperation. The extent to which mutual malevolent preferences reduce the opportunities to negotiate successfully depends on the shape and location of the utility curves. ${ }^{6}$ Thus, bargaining may fail when war does not entail these net costs, as psychological gains outweigh the costs of arming and destruction.

A third party wishing to facilitate a solution has to wait until the parties desire peace. Moreover, in the presence of vengeful feelings, and without genuine reconciliation, achieving a settlement might not suffice to start a process of relationship rebuilding. Rasmussen (2001) claims that traditional peace negotiations have been ineffective in repairing the relationship between the parties for three reasons. First, the goal of such negotiations is usually a "micro-level change in behavior" rather than to create the "attitudinal changes" which are crucial for the reconciliation between the disputants. Second, negotiations have always addressed tangible causes of conflict (e.g., land, property, and political structure) but failed to reach a deeper level of human psychological needs, such as recognition, justice, dignity, and identity. Third, traditional negotiations have not mapped out specific ways for belligerents to repair their relationship.

When such preferences are deeply rooted, punishment strategies will rarely succeed and hatred may well be strong enough to motivate belligerents to resist, even if this requires paying a high price. Preferences and emotions play a critical role in conflict, and a proper understanding of civil war resolution requires an integration of emotions into the other, more understood and better-developed causes of war.

The private provision of peace

Standard economic models assume that the peacekeeping actors are the governments of states with private, "national," interests who agree to provide the international public good of peacekeeping (see, e.g., Brauer, 2006; Berkok and Solomon, 2005) Yet states are not unitary rational actors. Instead, their decisions reflect the operation of coalitions of interests. Partly as a consequence of this incoherence, the justification for intervention, provided to internal or international audiences, may differ from the actual objectives of influential actors. Intervention motivations, as put forward by a number of scholars, mainly relate to humanitarian reasons, institutional arrangements, and strategic interests. 
Intervening for humanitarian reasons is a frequent justification for state intervention in civil wars. The preservation of human rights and the promotion of economic and social development are central themes in international law, but there are tradeoffs between these and state sovereignty, both of which are affirmed in the U.N. Charter. Chapter 7 (art. 41 and 42) authorizes the Security Council to introduce measures, including military actions, that may be necessary to maintain or restore international security against those responsible for threats to peace. The traditional view of Westphalian sovereignty prohibiting intervention in the internal affairs of other states is being reconsidered.

The decision to intervene for altruistic motives by a state may reflect public opinion and media pressure to stop human rights violations associated with civil wars, especially in democratic countries where popular consensus is vital to politicians seeking reelection. Diasporas from the country in conflict may exert pressure in the countries in which they live to intervene. Moreover, expatriate communities from the intervening countries living in the conflict zone, as well as past colonial links can also prompt intervention, such as individually-led military missions in former colonial spheres, such as Britain's in Sierra Leone and France's in Côte d'Ivoire.?

Yet, the participation in U.N. operations, although undertaken as part of a multilateral and internationally legitimized deployment, is subject to a formal approval at the state level. Differences in countries' institutional arrangements and some constitutional frameworks set limits on the action leaders can take (e.g., the parliament's veto power on the deployment of forces outside the state's boundaries). As opposed to Western countries, a weak system of checks and balances on executive action helps to explain the relative ease with which African countries deploy troops in U.N. operations.

There are many areas in the world that are considered strategically important, in ways that transcend altruistic motivations. Concern with vital resources has made Africa, the main area of peacekeeping, of more strategic interest to China, India, and Russia. Indeed, the continent has taken on increased relevance to the extent that its affairs affect energy security, but also immigration policies and transnational terrorism. The need to keep energy supplies flowing and international waterways accessible, two pillars in the American security policy for example, may also justify intervention.

However, different views about the primary function of the armed forces are the ultimate determinants. Some favor force projection over territorial defense. In the United Kingdom, for example, the sphere of influence and interests is deemed to be global and the image of the "guardian of the global order" is responsible for the currently prevailing attitude in favor of military intervention (Heiselberg, 2003). Conversely, there is a group of countries with long-standing foreign policy against sending troops abroad. While Germany, for instance, rejects its past military excess and its strategic culture values military force only as a deterrent, a "culture of restraint," the Austrian historical experience of being on the losing side in both world wars has created the feeling that security could better be achieved by neutrality (Giegerich, 2008).

In less democratic countries, other motivations are at play. For those that have experienced military involvements in state politics, peacekeeping insulates domestic politics from military interference by diverting armed forces from the domestic to the international arena, as in some Latin American states, the so-called "diversionary peace" (Norden, 1995). Governments that emerge from the authority of an external power or those formerly under a military regime may use peacekeeping to signal the end of an internationally ostracized government and the beginning of a new foreign policy era (Findlay, 1996). Argentina’s deployment of troops in U.N. peacekeeping operations (PKOs) was a way to regain prestige lost during the Falkland/Malvinas war (Sorenson and Wood, 2005). China, a nondemocratic country in the Security Council, may want to project the image of a responsible country, committed to sustaining the U.N. system. States are also drawn to the incentive of responsibility within or over a mission. Countries that are given operational command positions in the field tend to be more committed to operations (e.g., Brazil's participation to the mission in Haiti).

Given these explanations, peacekeeping can be interpreted as a self-interested action to preserve or increase a country's standing in the global arena. Doubtless, peacekeeping enhances a country's reputation and prestige, and therefore it is not only the armed forces that seek a role and gain benefits, but also the foreign ministry, "perhaps prodded by its mission to the UN in New York" (Findlay, 1996).

Given the variety of domestic and international factors that determine a country's contribution to military peacekeeping, there must be a question as to whether all this can be captured in a single objective function that can generate testable hypotheses. The next part of this section explores question this with an example.

The problem of troop contribution

The appendix provides a neoclassical model on the private provision of public goods, i.e., peace. The state is viewed as a rational actor, with a set of preferences. It maximizes its utility subject to a resource constraint. The model predicts a number of factors that are likely to explain the contribution to peacekeeping operations. In particular

- The unit cost of a soldier — or the statistical value of his life-and the expected marginal cost of casualties affect the participation dilemma (equations 3 and 4).

- The value placed on global stability and the proximity to the conflict area drive state-specific responses (equation 2 ).

- Countries face a troop constraint when choosing between a peacekeeping mission $\left(\mathrm{t}_{\mathrm{i}}\right)$ and other military activities, including concurrent peace operations $\left(\mathrm{s}_{\mathrm{i}}\right)$. They may not be willing to bear the additional burden of a new deployment when they already have committed forces elsewhere (equation 5). 
- An increase in other countries' contribution to an operation decreases a country's provision of troops to the same operation. This denotes a typical free-riding behavior (equation 10).

Some of the predictions of the theoretical model and some of the factors described in the previous section are tested through a panel data analysis against a data set on troop contributions across 102 states and 45 operations from 1999 to 2009. Both the likelihood of intervention (only for U.N. missions) and the size of the participation are investigated (for U.N. and non-U.N. operations, e.g., AU, NATO, and EU). Conflict characteristics identify which types of conflicts attract outside intervention; and the characteristics of the intervener identify which states are more willing to provide troops than others (Table 1). The empirical results suggest that at the donor level, the comparative advantage in manpower $\left(\mathrm{N}_{\mathrm{i}}\right.$ in the model), proxied by the number of armed forces, plays a big role. The risk of casualties [R(M) in the model], measured by the number of deaths among the peacekeepers and the number of concurrent operations $\left(\mathrm{s}_{\mathrm{i}}\right)$ is an important obstacle in non-UN operations. States abstain from engaging in operations with a high level of casualties among peacekeepers. The results also suggest that the unit cost of a soldier, or the "value of life" (equations 3 and 4), proxied by the real per capita GDP and the tertiary enrollment ratio, negatively affect the likelihood and size of participation. At the conflict/operation level, the security threat that a conflict poses, measured by conflict intensity, and the proximity to the conflict area, captured by the distance between donor and host country and the same geographical area dummy, influence the likelihood and size of intervention.

Overall, the results find that donors' characteristics are as important as the features of the country in conflict. Certainly, one of the most robust explanation of when states choose to intervene is the proximity to the conflict: When a conflict is regarded as a threat to global or regional stability, security concerns will trigger state-specific responses.

Conclusion

How useful is the economic approach in helping a peacekeeping third party to provide the right incentives for peace? Standard two-party models of conflict do not always provide a convincing tool to understand conflict resolution, even when economic factors are central. While they assimilate war and search for profit, implying that the main cause of war is the personal enrichment, the mediation and bargain process may be difficult to implement because of poor communication and fear that limit the room for solutions. Wrong perceptions, such as the overestimation of one's own relative ability, can affect the size of the settlement region, or its very existence. In this scenario, a successful intervention depends on a third party's ability to reorient the belligerents' perceptions and estimation about their chances of winning, the time

Table 1: Summary of empirical findings

Variable

Proxy for ... $\quad$ UN op's

non-UN op's

Likelihood

Operation and conflict characteristics

no. of death per year conflict intensity

same geographical area distance

no. of concurent PKOs

real per cap. GDP

tert. enrollm’t ratio (\%)

mil. exp/GDP (\%)

no. in armed forces risk of casualties positive global stability positive* proximity positive* proximity negative*

Donor characteristics

sustainability of inversely multiple ops U-shaped value of life negative* value of life negative* weight of the negative military

advantage in insignificant manpower

Size

Operation and conflict characteristics no. of death per year conflict intensity

no. of concurrent PKOs

real per cap. GDP tert. enrollm't ratio (\%) mil. exp/GDP (\%)

no. in armed forces risk of casualties positive global stability positive*

\section{Donor characteristics}

sustainability of insignificant multiple op's

value of life

value of life

weight of the

military

advantage in

manpower negative* positive*

negative* negative* insignificant insignificant insignifican insignificant positive* insignificant
* Results are those that are expected. 
required, and the expected payoffs from winning versus accepting a settlement. Yet, a significant obstacle to conflict resolution can also operate via mutual mistrust, fear, and hatred. Even when a peace agreement is reached, if the root causes that triggered the desire for vengeance are not addressed, the risk of relapse into conflict is inevitably high.

But, thus far, only strategies of reactive intervention have been considered. Preventative intervention, aimed to reduce the scale of conflicts by finding solutions at an early stage (e.g., by observing early warning signs) should also be regarded as effective. Indeed, the causes of many societal breakdowns tend to be structural, and thus might be addressed in a preventative manner. For example, stability guarantees for those weak states that have not already broken down in conflict is the easiest and most efficient external assistance one can supply and should give higher returns. A credible commitment of support by a number of states with well-equipped forces, and a proven record of success, would be necessary.

This leads to a need to explain how states decide to intervene in peace operations. Understanding this process is crucial because in the last few years the supply side of peace operations has come under difficult strains. A state's decision to intervene is based on self-interest, combined with a geostrategic dimension, and constrained by domestic and technical considerations. The research findings summarized here help to explain why the surge of violence in many parts of the world, Africa in particular, saw many overstretched operations, close to collapse on the ground, while conflicts in the Balkans and in Lebanon have been tackled more quickly and with a large deployment of forces. One of the greatest challenges is to account for concerns over the risk of casualties, which can hamper willingness to participate. In this respect, case studies can give additional insights. The Somali debacle in 1992 and the failed U.S. intervention there had repercussions around the world. Henceforth, before offering any military support to the U.N., the United States had to be satisfied that a vital national interest was at stake and that the mission was clearly defined in scope, size, and duration. But intolerance of casualties has not prevented the U.S. from intervening in Afghanistan and Iraq to topple the ruling regimes there. Further work along these lines, including additional data collection, would probably lead to more robust explanations.

The attempt to decompose peacekeeping into a demand for intervention and into a supply side-including its constituent elements of state interests and military capabilities — can generate valuable insights. Explaining obstacles to the demand for peace and the interests involved in peacekeeping is a crucial means of understanding the political dynamics of peacekeeping and of the actors involved in constructing peacekeeping as a global institution.

\section{Appendix: A model of troop contribution}

To study the problem of troop contribution, we consider two military goods. One, $\mathrm{s}_{\mathrm{i}}$, is private, say the number of troops employed within a state's boundaries. The other, $\mathrm{T}$, is a public good, which is the size of state i's own peacekeeping contributions, $\mathrm{t}_{\mathrm{i}}$, and those of the other $n-i$ nations, $T_{n-1}$. The states initially have some endowment of the private good, $\mathrm{N}_{\mathrm{i}}$, and determine how much to contribute to the public good. Each state faces a troop constraint when choosing among peacekeeping, $t_{i}$, and other military activities, $\mathrm{s}_{\mathrm{i}}$. If state i decides to contribute $\mathrm{t}_{\mathrm{i}}$, it will have $\mathrm{s}_{\mathrm{i}}=\mathrm{N}_{\mathrm{i}}-\mathrm{t}_{\mathrm{i}}$ of private security consumption left. The primary function of armed forces personnel, $\mathrm{N}_{\mathrm{i}}$, is the protection from foreign threats, but they also are used in public safety roles with police duties among the civilian population and in emergency civil support tasks in post-disaster situations. All these duties are captured by $\mathrm{s}_{\mathrm{i}}$. In case of multiple peacekeeping operations, $s_{i}$ captures not only the home defense, but also the troops already committed to other operations (e.g., Afghanistan or Iraq). Each unit of peacekeeping generates two joint products, a private benefit, $\alpha \mathrm{t}_{\mathrm{i}}$, and a global purely public characteristic, $\beta \mathrm{t}_{\mathrm{i}}$. The symbols $\alpha$ and $\beta$ are positive parameters and account for the coexistence of altruistic motivations $(\beta)$ with the egoistic considerations $(\alpha)$ of intervening states.

Assume that the outcome of the intervention is decided by state i's participation and the coalition's relative investment in fighting. The probability of success, $\sigma$, is a ratio given by

$$
\sigma\left(t_{i}\right)=\left(T_{n-1}+t_{i}\right) /\left(M+T_{n-i}+t_{i}\right)
$$

where the intervener fighting effort is measured by the scale of its deployment and $\mathrm{M}$ is the belligerents' strength and thus their resistance against third party involvement. When $\mathrm{t}_{\mathrm{i}}=\mathrm{T}_{\mathrm{n}-\mathrm{i}}=0$, there are no chances that the conflict will be settled without any third party involvement. Let us define a utility function, which captures the optimal number of troops to dispatch in peace operations. ${ }^{8}$ Because peacekeeping does not exclusively generate pure public benefits (e.g., peace and global stability), it also produces some excludable and rival contributor-specific benefits (e.g., protecting the expatriate community). With an adaptation of Khanna's, et al (1999) model, state i's expected utility function can be written as follows:

\section{(2) $\quad E U_{i}=\sigma\left(t_{i}\right) U\left[\alpha t_{i}, \beta\left(t_{i}+T_{n-1}\right), s_{i}, Q\right]-C_{i}\left(t_{i}\right)$}

$\mathrm{Q}$ is added to the function to capture any factor that can influence the utility from peacekeeping, such as the international security threat posed by the conflict and the proximity to the conflict area. $\mathrm{C}_{\mathrm{i}}\left(\mathrm{t}_{\mathrm{i}}\right)$ are the costs of participation. Accounting for the cost of a peace mission is not easy and, as pointed out by Fetterly (2006), there might be some hidden costs involved. ${ }^{9}$ Besides the military cost, the most important is the loss of life among peacekeepers. The value of life is usually compared to the discounted value of earnings foregone by individuals. The model assumes that the cost function can be expressed as 


$$
\text { (3) } \mathrm{C}_{\mathrm{i}}\left(\mathrm{t}_{\mathrm{i}}\right)=\mathrm{wt}_{\mathrm{i}} \mathrm{R}(\mathrm{M}) \text {, }
$$

where $w$ is the unit cost of a soldier, i.e., the value of life, and the function $\mathrm{R}$ measures the risk of the mission, which is increasing in its argument M. A traditional peacekeeping force in the midst of active and heavy hostilities, captured by a high value of the hostile parties' strength $M$, might not have the capacity to suppress the conflict and may even be limited in its ability to defend itself. On the contrary, low values of $\mathrm{M}$ result in higher odds of establishing peace (equation 1) and a lower risk of casualties (equation 3). Defining $\mathrm{x}$ as the state-specific output, $\alpha \mathrm{t}_{\mathrm{i}}$, and $\mathrm{y}$ as the global public characteristics, $\beta t_{i}$, the first order condition for $t_{i}$ can be found by maximizing equation (2) and rewriting this as

$$
\sigma^{`}\left(\mathrm{t}_{\mathrm{i}}\right) \mathrm{U}_{\mathrm{i}}+\sigma\left(\mathrm{t}_{\mathrm{i}}\right)\left[\left(\alpha \delta \mathrm{U}_{\mathrm{i}}\right) /(\delta \mathrm{x})+\left(\beta \delta \mathrm{U}_{\mathrm{i}}\right) /(\delta \mathrm{y})\right]=\sigma\left(\mathrm{t}_{\mathrm{i}}\right) \delta \mathrm{U}_{\mathrm{i}} /\left(\delta \mathrm{s}_{\mathrm{i}}\right)+\mathrm{wR}(\mathrm{M}) \text {. }
$$

The condition for efficiency is that the marginal benefit of providing peacekeeping (left-hand side of equation 4) equals the marginal costs (right-hand side). The marginal benefit is the sum of the utility weighted by the marginal impact of a soldier on the probability that intervention will be successful, and the marginal utility of the private and purely public activity weighted by the probability of success. The marginal benefit is offset by the sum of the opportunity cost of having fewer soldiers left for home duty times the probability of success, and the expected marginal cost of casualties.

To describe the Nash equilibrium and to obtain the reaction function of state $\mathrm{i}$, one proceeds as follow. Simplify the model by normalizing the exogenous parameters $\alpha, \beta$, and $Q$ and the endogenous probability of success, $\sigma$. The quantity of a state i's provision of the public good is still denoted by $t_{i}$. One unit of $t_{i}$ is also the quantity of the impure public good and its private characteristics. Letting $\mathrm{T}=\sum^{\mathrm{n} i=1} \mathrm{t}_{\mathrm{i}}=\mathrm{T}_{\mathrm{n}-\mathrm{i}}+\mathrm{t}_{\mathrm{i}}$, the utility maximization problem can be written as

$$
\operatorname{Max}_{\mathrm{si}, \mathrm{i}}\left[\mathrm{U}_{\mathrm{i}}\left(\mathrm{s}_{\mathrm{i}}, \mathrm{t}_{\mathrm{i}}, \mathrm{T}\right) \text {, s.t. } \mathrm{s}_{\mathrm{i}}+\mathrm{t}_{\mathrm{i}}=\mathrm{N}_{\mathrm{i}}, \mathrm{T}=\mathrm{T}_{\mathrm{n}-\mathrm{i}}+\mathrm{t}_{\mathrm{i}}\right] \text {, }
$$

where the rescaled utility function, $U_{i}$, keeps the properties of being strictly increasing and quasiconcave. Adding $\mathrm{T}_{\mathrm{n}=\mathrm{i}}$ to both sides of the budget constraint and using the fact that $\mathrm{T}=\mathrm{T}_{\mathrm{n}-\mathrm{i}}+\mathrm{t}_{\mathrm{i}}$, one can rewrite this state's problem as

$$
\operatorname{Max}_{\mathrm{si}, \mathrm{i}}\left[\mathrm{U}_{\mathrm{i}}\left(\mathrm{s}-_{\mathrm{i}}, \mathrm{t}_{\mathrm{i}}, \mathrm{T}\right) \text {, s.t. } \mathrm{s}_{\mathrm{i}}+\mathrm{T}=\mathrm{N}_{\mathrm{i}}+\mathrm{T}_{\mathrm{n}-\mathrm{i}}, \mathrm{T} \geq \mathrm{T}_{\mathrm{n}-\mathrm{i}}\right] \text {. }
$$

Equation 6 says that a state $\mathrm{i}$ is choosing the total amount of peacekeeping subject to the constraint that the amount it chooses must be at least as large as the amount provided by the other countries. The troop constraint says that the total value of its security consumption must equal the value of its troop endowment, $\mathrm{N}_{\mathrm{i}}+\mathrm{T}_{\mathrm{n}-\mathrm{i}}$. Substituting the constraints into the objective function, one can rewrite this problem as a choice over the aggregate (global) level of peacekeeping:

(7) $\quad \operatorname{Max}_{T \geq T n-i}\left[U_{i}\left(N_{i}+T_{n-i} T, T-T_{n-i}, T\right)\right]$.

Problem 7 is like any consumer maximization problem, and a state's optimal choice of peacekeeping, $\mathrm{T}$, will be a continuous function of its national endowment:

(8) $\quad F_{i}\left(N_{i}+T_{n-i}, T_{n-i}\right) \geq T_{n-i}$.

Each state's level of private provision of peacekeeping can be written as

(9) $t_{i}=F_{i}\left(N_{i}+T_{n-i}, T_{n-i}\right)-T_{n-I} \geq 0$.

This expression is the reaction function for state $i$ and gives its optimal contribution as a function of the other states' contribution.

Typically, in models of private provision of private goods, a further assumption is the normality condition, satisfied if both the private and public goods are normal with respect to troop endowment (i.e., $\mathrm{N}_{\mathrm{i}}+\mathrm{T}_{\mathrm{n}-\mathrm{i}}$ ). The assumption is stated as

$$
0 \leq \delta F_{i} / \delta T_{n-i} \leq 1
$$

This implies that reaction functions have slopes greater than -1 and less than or equal to zero. Therefore, an increase in other states' contribution, $\mathrm{T}_{\mathrm{n}-\mathrm{i}}$, must increase its demand for the public good and not decrease its demand for the private good.

An alternative formulation to obtain the best-response function is

(11) $\mathrm{t}_{\mathrm{i}}=\operatorname{Max}\left[\mathrm{F}_{\mathrm{i}}\left(\mathrm{N}_{\mathrm{i}}+\mathrm{T}_{\mathrm{n}-\mathrm{i}}\right)-\mathrm{T}_{\mathrm{n}-\mathrm{i}}, 0\right]$.

This last expression shows that each state either contributes a positive amount or completely free rides and contributes zero. Finally, a Nash equilibrium is a set of contributions, $\left\{\mathrm{t}_{\mathrm{i}}\right\}_{\mathrm{i}=1 \mathrm{n}}$, that satisfies the aggregation rule, $\mathrm{T}^{*}=\sum^{\mathrm{ni}=1} \mathrm{t}_{\mathrm{i}^{*}}$. Kotchen (2007) provides a proof of existence and uniqueness of this Nash equilibrium in an impure public good model.

Notes

Vincenzo Bove is Postdoctoral Fellow in the Department of Government at the University of Essex, United Kingdom. He may be reached at <vbove@essex.ac.uk>. I am grateful to Ron Smith for his invaluable advice and to Jurgen Brauer, Paul Dunne, and Gerard Padró i Miquel for their helpful comments. The usual disclaimer applies. 


\section{Diehl (2008).}

2. For a review of civil war, see Blattman and Miguel (2010).

3. Grossman(1991), Hirshleifer (1995); Skaperdas (1992).

4. Bove and Smith (2011); Bove (2011).

5. Kim and Smith (1993).

6. Anderton and Carter (2009).

7. Germany's participation in the U.N. Transition Assistance Group (UNTAG) in Namibia was vital for the protection of 20,000 German-Namibians.

8. The utility, defined over the space of private and public characteristics, is strictly increasing in consumption of both the private and the public good, quasiconcave, continuous, and everywhere twice differentiable.

9. SIPRI provides budget costs for U.N. multilateral peace operations. They refer to core operational costs, which include the cost of deploying personnel and direct nonfield support costs. The cost is shared by all U.N. member states through a specially designed scale of assessed contributions that takes no account of their participation in the operations.

\section{References}

Anderton, C.H and J.R Carter. 2009. Principles of Conflict Economics. New York: Cambridge University Press.

Berkok, U. and B. Solomon. 2005. Introduction. Defence and Peace Economics. Vol. 16, No. 3 pp. $143-144$.

Blattman, C. and M. Edward. 2010. “Civil War” Journal of Economic Literature. Vol. 48, No. 1, pp. 3-57.

Bove, V. 2011 “The Supply and Demand for Peacekeeping. Ph.D. thesis. Birkbeck, University of London.

Bove, V. and R. Smith. 2011. “The Economics of Peacekeeping,” pp. 237-264 in D. Braddon and K. Hartley, eds., Handbook on the Economics of Conflict. Cheltenham, UK: Elgar..

Brauer, J. 2006. "Theory and Practice of Intervention.” Economics of Peace and Security Journal. Vol. 1, No. 2, pp. 17-23.

Brauer, J and J.P. Dunne. 2006. "Peacemaking and Peacekeeping: Introduction.” Economics of Peace and Security Journal. Vol. 1, No. 2 pp. 1-3.
Diehl, P. 2008. Peace Operations. Cambridge, UK: Polity Press.

Fetterly, R. 2006. "The Cost of Peacekeeping: Canada.” Economics of Peace and Security Journal. Vol. 1, No. 2, pp. 47-53.

Findlay, T. 1996. “The New Peacekeepers and the New Peacekeeping.” Working Paper. Canberra: Australian National University.

Giegerich, B. 2008. European Military Crisis Management: Connecting Ambition and Reality. London: Adelphi Paper, No. 397.

Grossman, H.I. 1991. “A General Equilibrium Model of Insurrections.” American Economic Review. Vol. 81, No. 4, pp. 912-921.

Heiselberg, S. 2003. Pacifism or Activism: Towards a Common Strategic Culture within the European Security and Defence Policy? Copenhagen: Danish Institute for International Studies.

Hirshleifer. J. 1995. “Anarchy and its Breakdown.” Journal of Political Economy. Vol. 103, pp.:26-52.

Hirshleifer, J. 1999. “The Bioeconomic Causes of War.” Managerial and Decision Economics. Vol. 19, Nos. 7-8, pp. 457-466

Khanna, J, T. Sandler, and H. Shimizu. 1999. "The Demand for UN Peacekeeping, 1975-1996.” Kyklos. Vol. 52, No. 3, pp. 345-368.

Kim, S. and R.H. Smith. 1993. "Revenge and Conflict Escalation.” Negotiation Journal. Vol. 9, pp. 37-43.

Kotchen, M.J. 2007. "Equilibrium Existence and Uniqueness in Impure Public Good Models.” Economics Letters. Vol. 97, No. 2, pp. 91-96.

Norden, D. 1995. "Keeping the Peace, Outside and In: Argentina's UN Missions.” International Peacekeeping. Vol. 2, No. 3, pp. 330-349.

Rasmussen, J.L. 2001. Reconciliation, Justice, and Coexistence: Theory and Practice. Lanham, MD: Lexington Books.

Regan, P. 1996. "Conditions of Successful Third-Party Intervention in Intrastate Conflicts.” Journal of Conflict Resolution. Vol. 40, No. 2, pp. 336-359.

Skaperdas, S. 1992. "Cooperation, Conflict, and Power in the Absence of Property Rights.” American Economic Review. Vol. 82, No. 4, pp.:720-739.

Sorenson, D. and P. Wood. 2005. The Politics of Peacekeeping in the Post-Cold War Era. London]: Frank Cass.

Wittman, D. 1979. "How a War Ends: A Rational Model Approach.” Journal of Conflict Resolution. Vol. 23, No. 4, pp. 7430763. 